\title{
ESTUDO ISOTÓPICO Sm-Nd REGIONAL DA PORÇÃO CENTRAL DA FAIXA BRASÍ- LIA, GOIÁS: IMPLICAÇÕES PARA IDADE E ORIGEM DOS GRANULITOS DO COM- PLEXO ANÁPOLIS-ITAUÇU E ROCHAS METASSEDIMENTARES DO GRUPO ARAXÁ
}

\author{
MÁRCIO MARTINS PIMENTEL*, REINHARDT ADOLFO FUCK* E DANIELLE PIUZANNA FISCHEL
}

\begin{abstract}
REGIONAL Sm-Nd ISOTOPIC STUDY OF THE CENTRAL PART OF THE BRASILIA BELT, GOIÁS: IMPLICATIONS FOR THE AGE AND ORIGIN OF THE ANÁPOLIS-ITA UÇU GRANULITIC COMPLEX AND METASEDIMENTARY ROCKS OF THEARAXA GROUP In the central part of the Brasilia Belt, central Brazil, a high grade terrain, the Anápolis-Itauçu Complex, is exposed within the metasedimentary rocks of the Araxá Group.

The Anápolis-Itauçu Complex in Goiás represents a complex association of high-grade rocks including mafic-ultramafic bodies, charnockites, enderbites, as well as aluminous granulites of sedimentary origin, associated with marbles and quartzites. Narrow volcano-sedimentary belts formed mainly by amphibolites and micaschists are also recognized within the complex. This high-grade terrain has been traditionally interpreted as part of the old (Archaean/Paleoproterozoic) sialic basement to the Neo- or Mesoproterozoic sediments of the Araxá Group, Brasilia Belt. The granulites and metasediments of the Araxá Group are intruded by a large number of granite intrusions, many of which show peraluminous character.

$\mathrm{Sm}-\mathrm{Nd}$ isotopic analyses for the garnet- and sillimanite-bearing aluminous granulites indicate $\mathrm{T}_{\mathrm{DM}}$ model ages between ca. 1.3 and $1.6 \mathrm{Ga}$. These values represent the upper limit for the age of the protoliths of the granulites, demonstrating that they are (at least in part) younger than suggested in previous models.

The intrusive granites have a Sm-Nd isotopic pattern which is not much different from that observed for the felsic granulites, with TDM model ages ranging in the interval between ca. 1.37 and $1.85 \mathrm{Ga}$. The isotopic compositions of the granitic and granulitic rocks investigated are also similar to those determined for metasediments of the internal zone of the Brasilia Belt (Araxá Group) in central-southern Goiás. These metasediments show $\mathrm{Nd}$ model ages between ca. 1.2 and $2.2 \mathrm{Ga}$.

The preliminary isotopic data presented are consistent with a model in which the voluminous granitic magmatism identified in the Anápolis-Itauçu Complex and adjacent areas is Neoproterozoic in age, being the result of re-melting of the older sialic crust. The peraluminous nature of many of these granites/rhyolites (e.g. the Maratá Sequence and associated granites in the Ipameri area) indicates that the original magmas were mostly extracted from a metasedimentary source which is isotopically similar to the metasedimentary rocks of the Araxá Group.

We suggest a model in which at least part of the aluminous granulites of the Anápolis-Itauç Complex represents high-grade equivalents of the metasedimentary sequences of the internal part of the Brasilia Belt.

Keywords: granulites, metasedimentary rocks, Brasilia Belt, model age, Sm-Nd

RESUMO A porção central da Faixa Brasília é caracterizada pela exposição de terrenos de alto grau, constituinda o chamado Complexo Anápolis-Itauçu, exposto em meio a rochas metassedimentares do Grupo Araxá.

O Complexo Anápolis-Itauçu, em Goiás, compreende uma associação de rochas de alto grau metamórfico constituído por: (i) granulitos ortoderivados, incluindo corpos máfico-ultramáficos, charnoquitos, enderbitos, gnaisses tonalíticos e (ii) granulitos aluminosos paraderivados associados a mármores e sillimanita quartzitos. Estreitas faixas de seqüências vulcano-sedimentares constituídas predominantemente por anfibolitos e micaxistos também são reconhecidas. Instrusivos nas rochas de alto grau e também nos metassedimentos do Grupo Araxá, e conhecido um grande número de corpos graníticos, muitos dos quais apresentando caráter peraluminoso. Esse conjunto de rochas tem sido tradicionalmente interpretado como parte do embasamento siálico antigo (Paleoproterozóico ou Arqueano) dos metassedimentos neoproterozóicos da Faixa Brasília.

Análises Sm-Nd em amostras de granulitos félsicos aluminosos, portadores de sillimanita e granada, indicam idades modelo $\mathrm{T}_{\mathrm{DM}}$ entre ca. 1,3 e 1,6 Ga. Esses valores representam um limite superior para a idade dos protólitos dessas rochas de alto grau e revelam que elas são mais jovens do que o postulado em modelos anteriores.

Granitos intrusivos no Complexo Anápolis-Itauçu e nos metapelitos do Grupo Araxá em regiões adjacentes ao complexo granulítico apresentam um padrão isotópico de Nd semelhante ao observado para os granulitos félsicos, com idades modelo variando entre 1,37 e 1,85 Ga. As composições isotópicas de $\mathrm{Nd}$ das rochas granulíticas e graníticas investigadas são, por sua vez, parecidas com as dos metassedimentos que constituem a zona interna da Faixa Brasília (Grupo Araxá) na região centro-sul de Goiás, os quais mostram idades modelo entre ca. 1,2 e 2,2 Ga.

Os dados isotópicos preliminares são consistentes com um modelo no qual o magmatismo granítico de natureza em parte peraluminosa, associado ao Complexo Anápolis-Itauçu, é de idade Neoproterozóica, sendo o resultado da refusão de material siálico pré-existente. O caráter aluminoso de muitos desses granitóides e riolitos (e.g. Seqüência Maratá e granitos associados, na região de Ipameri) sugere uma fonte metassedimentar, indistinta isotopicamente das rochas metassedimentares do Grupo Araxá. As composições isotópicas de Nd dos granulitos félsicos sugerem ainda que, pelo menos em parte, essas rochas representam os correspondentes de alto grau metamórfico das seqüências supracrustais da porção interna da Faixa Brasília.

Palavras-chaves: granulitos, rochas metassedimentares, Faixa Brasília, idade modelo, Sm-Nd
\end{abstract}

INTRODUÇÃo A porção centro-sul da Faixa Brasília é caracterizada por: (i) granulitos e gnaisses do chamado Complexo Anápolis-Itauçu, (ii) metassedimentos pelíticos da zona interna da faixa dobrada, constituindo, especialmente, o Grupo Araxá, e (iii) granitos intrusivos tanto nos terrenos de alto grau como nas rochas supracrustais do Grupo Araxá.

Na Faixa Brasília rochas de fácies granulito ocorrem nos complexos máfico-ultramáficos de Barro Alto, Niquelândia e Cana Brava e no chamado Complexo Anápolis-Itauçu na porção centro-sul de Goiás. Em anos recentes, estudos geocronológicos e isotópicos detalhados em rochas dos grandes complexos diferenciados têm revelado idades de cristalização paleoproterozóicas e idades de metamorfismo de alto grau em torno de $780 \mathrm{Ma}$ (Ferreira Filho et al. 1994, Suita et al. 1994, Correia et al. 1997, 1998). Muito pouco se conhece, entretanto, sobre a geocronologia e características isotópicas das rochas de alto grau e granitos intrusivos do Complexo Anápolis-Itauçu. Esse complexo se estende desde as vizinhanças de Itauçu, a NW, até as cercanias de Ipameri no sudeste de Goiás, compreendendo uma faixa alongada na direção NW de cerca de $200 \mathrm{~km}$ de comprimento (Figura 1). Trata-se de uma intrincada associação de granulitos e gnaisses derivados tanto de rochas ígneas como sedimentares, que tem sido tradicionalmente interpretada como o embasamento siálico antigo da Faixa Brasília, provavelmente de idade arqueana (Marini et al. 1984, Danni et al. 1982, Wolff 1991), muito embora pouco se conheça a respeito de sua geocronologia. Neste trabalho reportamos e discutimos os primeiros dados Sm-Nd obtidos para amostras de diversos corpos graníticos que intrudem o Complexo Anápolis-Itauçu, bem como para metassedimentos que constituem a porção interna da Faixa Brasília. Muito embora os dados aqui reportados tenham um caráter regional e preliminar, eles permitem algumas conclusões relevantes em relação à natureza e idade das rochas do Complexo Anápolis-Itauçu e do magmatismo granítico associado.

CONTEXTO GEOLÓGICO REGIONAL A área investigada localiza-se na porção centro-sul de Goiás (Figura 1). Geologicamente é representada principalmente pelo chamado Complexo AnápolisItauçu, estando inserida na chamada zona interna da Faixa Brasília (Fuck et al 1994), desenvolvida durante o Neoproterozóico na margem ocidental do Cráton do São Francisco.

O Complexo Anápolis-Itauçu é constituído por uma grande variedade de tipos litológicos: (i) granulitos ortoderivados incluindo corpos máfico-ultramáficos granulitizados, constituídos por metagabros, metapiroxenitos, metanortositos, bem como corpos de composição charnoquítica e enderbítica, (ii) migmatitos e ortognaisses de 


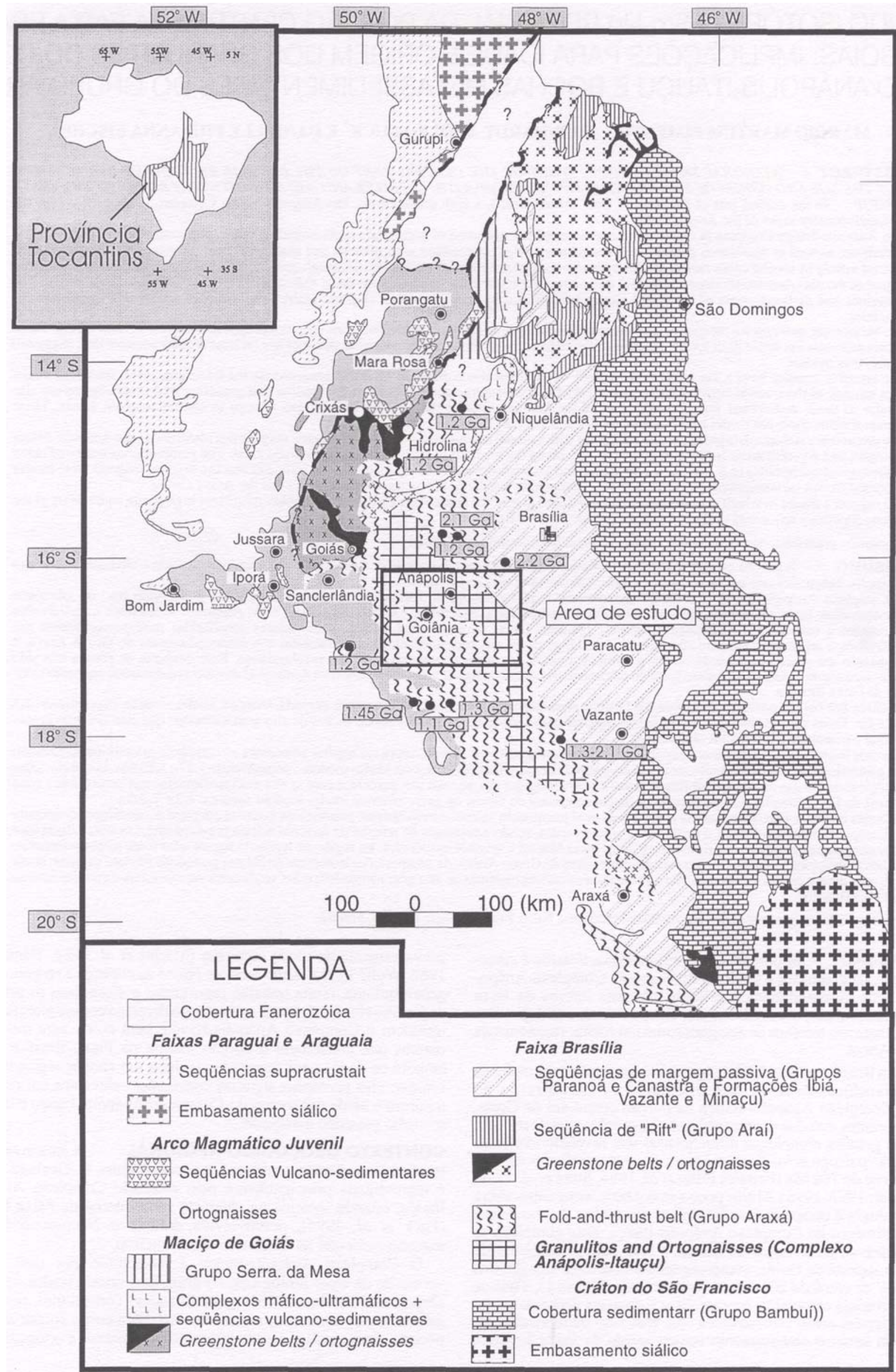

Figura l - Esboço geotectônico da Faixa Brasília e localização da área de estudo. 
composição tonalítica a granítica e (iii) um grande volume de granulitos e gnaisses aluminosos, contendo sillimanita e granada, eventualmente apresentando cordierita, espinélio e safirina, possivelmente derivados de sedimentos pelíticos a grauvaquianos (Araújo et al. | 994, Winge 1995, Wolff 1991). A esses granulitos aluminosos associam-se outras rochas de origem supracrustal tais como diopsídio mármores, calcissilicáticas, gonditos e sillimanita quartzitos. Entretanto, nem todas as rochas granulíticas portadoras de sillimanita e granada, no Complexo Anápolis Itauçu, são necessariamente paraderivadas. Algumas, por apresentar suas texturas ígneas ainda parcialmente preservadas, são consideradas como sucedâneas de intrusões graníticas. Na verdade, Wolff (1991) descreve a formação de leucossomas aluminosos, também recristalizados em alto grau metamórfico, derivados da fusão parcial de rochas granulíticas félsicas.

Todo esse conjunto de rochas foi interpretado por Wolff (1991), com base em dados de litogeoquímica e petrografia, como seqüências do tipo greenstone belts arqueanas, metamorfisadas em condições de fácies granulito.

As rochas granulíticas do complexo encontram-se limitadas pelas coberturas dobradas do Grupo Araxá, sendo as relações de contato de natureza tectônica, marcadas por extensas zonas de cisalhamento contracionais (cavalgamentos) e transcorrentes (Araújo 1994). O Grupo Araxá é também bastante diversificado litoloeicamente. abrangendo extensas unidades de micaxistos, paragnaisses, quartzitos e calcixistos. A elas também se associam: (i) seqüências vulcano-sedimentares representadas por anfibolitos, xistos feldspáticos e agalmatolitos, reunidos nas seqüências Silvânia (Valente 1986 in Lacerda Filho \& Oliveira 1994) e Rio do Peixe (Nascimento 1985 in Lacerda Filho \& Oliveira, 1994), e (ii) inúmeros corpos máfico-ultramáficos do tipo alpino tectonicamente interacamadados com gnaisses e metassedimentos de mar profundo, constituindo uma mélange ofiolítica (Strieder \& Nilson 1992).

$\mathrm{Na}$ região, o Grupo Araxá é constituído predominantemente por micaxistos feldspáticos localmente contendo anfibólio, granada, estaurolita e cianita, gnaisses finos e quartzitos. Wolff (1991) descreve locais onde incipiente migmatização atingiu os metassedimentos do Grupo Araxá.

As rochas de alto grau metamórfico, bem como os metassedimentos do Grupo Araxá, adjacentes ao Complexo Anápolis-Itauçu, são intrudidas por numerosos corpos de rochas granfticas de dimensões variadas (ver mapa da Figura 2), vários dos quais são formados por leucogranitos mostrando paragêneses minerais aluminosas (moscovita e granada) e enclaves de rochas metassedimentares. São interpretados, portanto, como granitos crustais, peraluminosos, provavelmente sincolisionais (Araújo 1994). Assim, é possível que algumas dessas intrusões reoresentem derivados anatéticos a partir das rochas
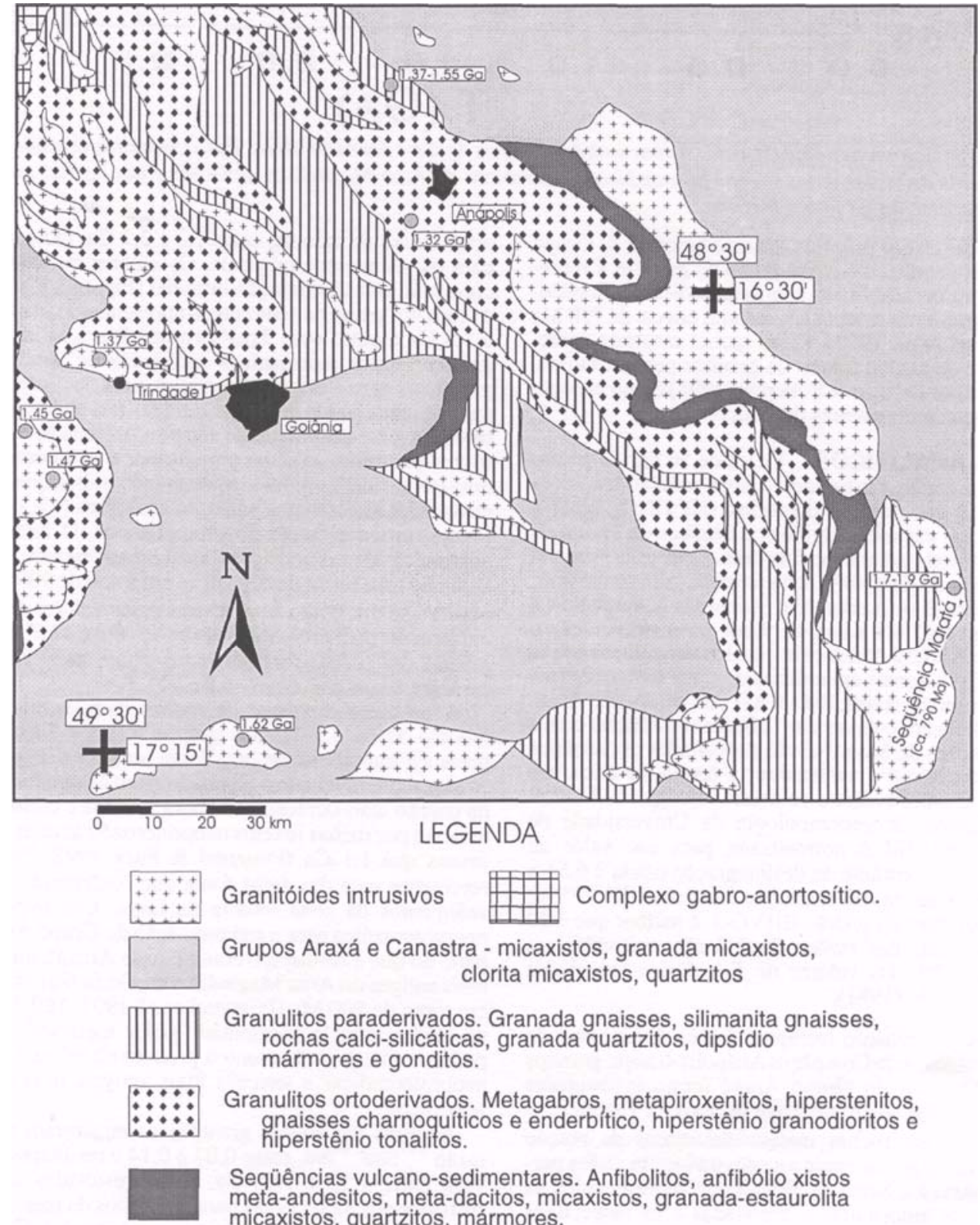

Granitóides intrusivos $\#$ Complexo gabro-anortosítico.

Grupos Araxá e Canastra - micaxistos, granada micaxistos, clorita micaxistos, quartzitos

Granulitos paraderivados. Granada gnaisses, silimanita gnaisses, rochas calci-silicáticas, granada quartzitos, dipsídio mármores e gonditos.

Granulitos ortoderivados. Metagabros, metapiroxenitos, hiperstenitos, gnaisses charnoguíticos e enderbítico, hiperstênio granodioritos e hiperstênio tonalitos.

Seqüências vulcano-sedimentares. Anfibolitos, anfibólio xistos meta-andesitos, meta-dacitos, micaxistos, granada-estaurolita micaxistos, quartzitos, mármores. 


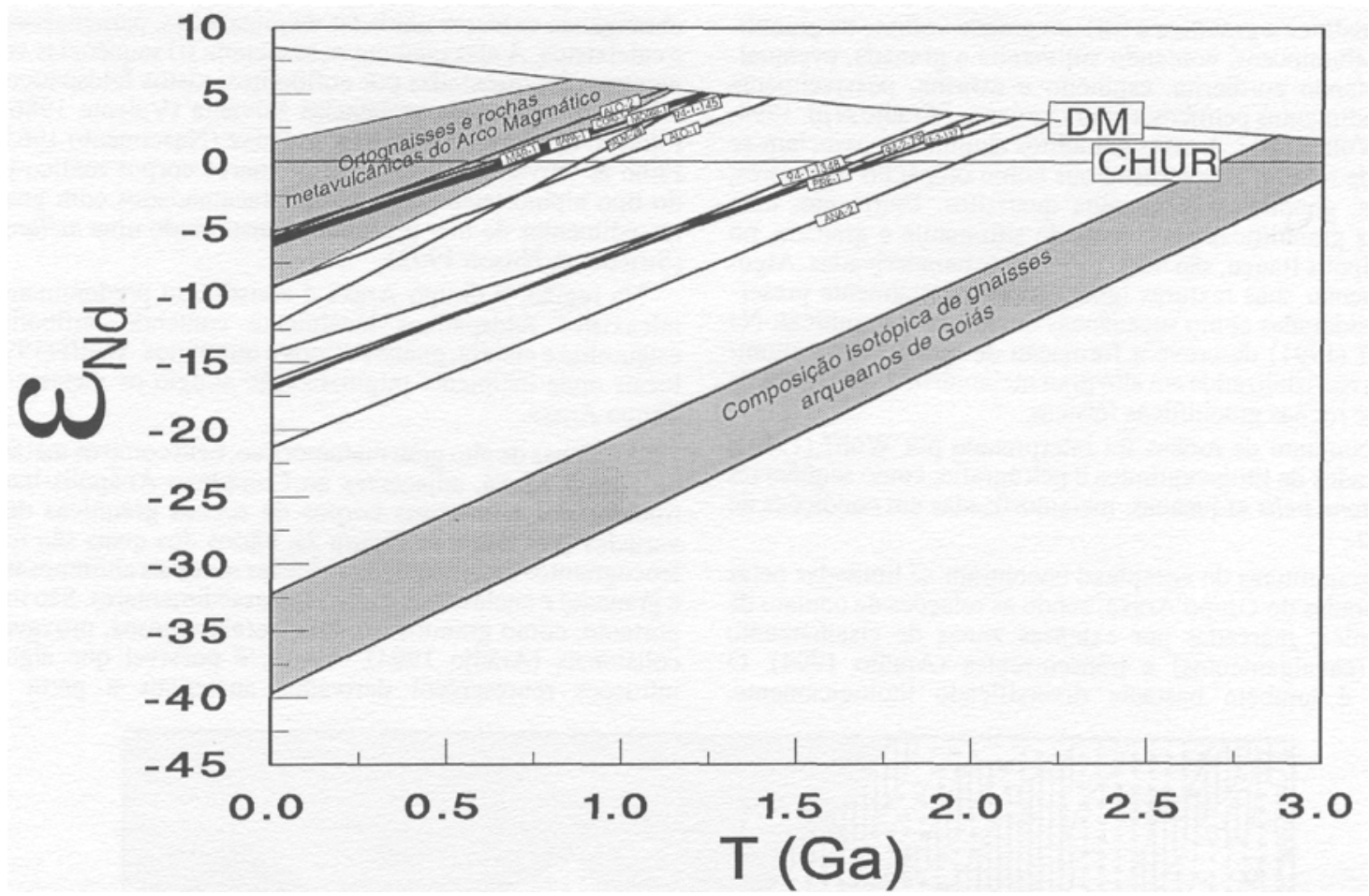

Figura 3 - Características isotópicas de Nd de metassedimentos dos Grupos Araxá e Serra da Mesa. Para comparação estão mostrados também os campos composicionais definidos pelas rochas juvenis Neoproterozóicas do Arco Magmático de Goiás e por rochas gnáissicas arqueanas de outras áreas do embasamento da Faixa Brasília.

granulíticas paraderivadas ou dos próprios metassedimentos do Grupo Araxá. Um exemplo bem conhecido desse grupo de granitos é representado pelas rochas graníticas/riolíticas neoproterozóicas da Seqüência Maratá e intrusões graníticas associadas, datadas em ca. de 790 Ma (dados U-Pb de Pimentel et al. 1992). Essas rochas mostram características geoquímicas e de campo típicas de granitos peraluminosos, tendo sido interpretadas por Ribeiro \& Pimentel (1998) como produto da refusão de rochas metassedimentares do Grupo Araxá.

PROCEDIMENTOS ANALÍTICOS Cerca de $50 \mathrm{mg}$ do pó das amostras de rocha-total foram misturados a uma solução traçadora mista de ${ }^{149} \mathrm{Sm}^{150} \mathrm{Nd}$ e em seguida digeridos $\left(\mathrm{HF}: \mathrm{HNO}_{3}\right.$ igual a aproximadamente 8:1) em cápsulas Savillex ou bombas de Teflon do tipo Parr ao longo de aproximadamente dois dias. Após essa primeira digestão, a solução é evaporada e novamente atacada com os mesmos ácidos por cerca de quatro dias. A solução é evaporada novamente e o resíduo solubilizado em $\mathrm{HC} 16 \mathrm{~N}$ a quente. Após nova evaporação o resíduo é solubilizado em $\mathrm{HC} 12,5 \mathrm{~N}$. A extração dos lantanídeos é feita através de métodos convencionais em colunas de troca iônica confeccionadas em quartzo, usando resina BIO-RAD AG-50W-X8. A extração de $\mathrm{Sm}$ e $\mathrm{Nd}$ foi feita em colunas em Teflon empacotadas com a resina LN-Spec. As frações de Sm e Nd são depositadas em arranjos duplos de filamentos de Rênio e analisadas na forma metálica, em modo estático, usando o espectrômetro de massa Finnigan MAT-262 multicoletor do laboratório de geocronologia da Universidade de Brasília. A razão ${ }^{143} \mathrm{Nd} /{ }^{144} \mathrm{Nd}$ é normalizada para um valor de ${ }^{146} \mathrm{Nd} /{ }^{144} \mathrm{Nd}$ de 0,7219 e a constante de desintegração usada é $6,54 \mathrm{x}$ $10^{-12} \mathrm{a}^{-1}$. A precisão externa na determinação da razão ${ }^{143} \mathrm{Nd} /{ }^{144} \mathrm{Nd}$, baseada em repetidas análises do padrão BHVO-1, é melhor que \pm 20 $\mathrm{ppm}$ ( 1 sigma). Incertezas nas razões $\mathrm{Sm} / \mathrm{Nd}$ são estimadas em aproximadamente $\pm 0.2 \%$. Os valores de $\mathrm{T}_{\mathrm{DM}}$ foram calculados usando o modelo de DePaolo (1981).

RESULTADOS A composição isotópica de $\mathrm{Nd}$ de amostras de granulitos félsicos aluminosos do Complexo Anápolis-Itauçu, granitos intrusivos e metassedimentos do Grupo Araxá foram investigadas neste trabalho e os resultados analíticos estão listados na Tabela 1.

Resultados isotópicos em rochas metassedimentares da porção interna da Faixa Brasília, especialmente moscovita/biotita xistos pertencentes aos grupos Araxá e Serra da Mesa estão representados na Figura 3. As localidades amostradas e analisadas e os respectivos valores de idades modelo estão indicados na Figura 1. Esses metassedimentos mostram valores homogêneos para as razões ${ }^{147} \mathrm{Sm} /{ }^{144} \mathrm{Nd}$, entre ca. 0,11 e 0,14 . As idades modelo de $\mathrm{Nd}$ distribuem-se em uma ampla faixa de valores, entre 1,2 e 2,2 Ga, indicando fontes variadas para os sedimentos originais. Os valores de idade modelo parecem constituir uma distribuicão bimodal (Figura 3 e histograma da Figura 4) com um grupo de sedimentos apresentando idades modelo entre 1,1 e 1,3 Ga e outro com $\mathrm{T}_{\mathrm{DM} \text { 's }}$ entre 1,9 e 2,3 Ga. Essa bimodalidade provavelmente representa a influência de pelo menos duas fontes principais para a origem dos sedimentos do Grupo Araxá. Em última análise, cada valor de idade modelo nos metassedimentos pode ser interpretado como idade de mistura, refletindo as características das fontes que foram erodidas para formar o sedimento original. O padrão bimodal de idades modelo apresentado indica que as fontes principais envolvidas são terrenos paleoproterozóicos $(<2,3 \mathrm{Ga})$ e terrenos mais jovens, provavelmente neoproterozóicos. O mesmo é observado se analisadas as composições isotópicas iniciais dessas rochas, assumindo uma idade de deposição em torno de 900 Ma. Para essa idade observa-se um grupo de amostras cujos valores de e(T) são predominantemente positivos, variando entre- $0,3 \mathrm{e}+3,3$, indicando a natureza juvenil das rochas-fonte, e outro grupo com valores de e(T) francamente negativos, entre $-6,8$ e -1 1,7.

A presença marcante de rochas metassedimentares com idades modelo de ca. 1,1-1,3 nos grupos Araxá e Serra da Mesa sugere a presença importante de uma fonte jovem na origem dos sedimentos. Assim, é provável que o chamado Arco Magmático de Goiás, exposto na porção mais ocidental da Faixa Brasília e constituído predominantemente por rochas juvenis neoproterozóicas com idades modelo mais jovens que 1,1 Ga (Pimentel \& Fuck 1992, Pimentel et al. 1997) represente uma das áreas fonte que contribuiu com detritos para os sedimentos da zona interna da faixa. Isso implica em uma idade neoproterozóica para a sedimentação do Grupo Araxá (ou pelo menos parte do que é conhecido como Grupo Araxá), uma vez que as rochas mais antigas do Arco Magmático de Goiás têm idades de cristalização em torno de $900 \mathrm{Ma}$ (Pimentel et al. 1991, 1997). Portanto, o padrão de idades modelo apresentado pelos metassedimentos investigados pode ser interpretado como o produto da mistura entre fontes juvenis neoproterozóicas e terrenos mais antigos, provavelmente paleoproterozóicos.

Análjses das rochas granulíticas mostraram valores variáveis da razão ${ }^{147} \mathrm{Sm} /{ }^{144} \mathrm{Nd}$, entre 0,07 e 0,14 e resultaram em idades modelo $\mathrm{T}_{\mathrm{DM}}$ entre 1,32 e 1,55 Ga. Esses resultados são semelhantes aos relatados por Sato (1 998) para granulitos da mesma região (Fig. 5),os quais indicam idades modelo entre 1,2 e 1,4 Ga. Muito embora as idades de cristalização/deposição original dessas rochas ainda não sejam conhecidas, as idades modelo obtidas estabelecem um limite 
Tabela 1 - Dados isotópicos Sm-Nd

\begin{tabular}{|c|c|c|c|c|c|c|}
\hline Amostra & Sm(ppm) & Nd(ppm) & ${ }^{147} \mathrm{Sm}^{1144} \mathrm{Nd}$ & ${ }^{143} \mathrm{Nd} / /^{144} \mathrm{Nd}( \pm 2 \mathrm{SE})$ & $\varepsilon_{\mathrm{Nd}}(0)$ & $\begin{array}{l}T_{\mathrm{DM}} \\
(\mathrm{Ga})\end{array}$ \\
\hline \multicolumn{7}{|c|}{ Granulitos félsicos aluminosos } \\
\hline ANA-1 & 15.79 & 137.7 & 0.069 & $0.511779(05)$ & $-16,8$ & 1.32 \\
\hline GO-1-I & 4.607 & 20.31 & 0.137 & $0.512260(05)$ & -7.4 & 1.55 \\
\hline GO-1-II & 4.335 & 21.06 & 0.124 & $0.512237(05)$ & -7.8 & 1.37 \\
\hline \multicolumn{7}{|l|}{ Rochas graníticas } \\
\hline ANIC-1B & 1.903 & 8.321 & 0.138 & $0.512118(07)$ & $-10,1$ & 1.85 \\
\hline CAMP-1 & 4.466 & 26.19 & 0.103 & $0.511963(08)$ & $-13,2$ & 1.47 \\
\hline STABO-1 & 15.06 & 86.21 & 0.105 & $0.511988(05)$ & $-12,7$ & 1.45 \\
\hline TRI-1 & 12.29 & 85.46 & 0.087 & $0.511895(05)$ & $-14,5$ & 1.37 \\
\hline CROM-1B & 4.302 & 23.25 & 0.112 & $0.511950(05)$ & $-13,4$ & 1.62 \\
\hline GO-19C & 5.038 & 20.46 & 0.149 & $0.512085(05)$ & -10.8 & - \\
\hline GO-19E & 6.032 & 24.98 & 0.146 & $0.512038(05)$ & -11.7 & - \\
\hline GO-19A & 4.161 & 16.69 & 0.151 & $0.512062(05)$ & -11.2 & - \\
\hline MP-594N* & 7.301 & 40.65 & 0.109 & $0.511853(05)$ & -15.7 & 1.73 \\
\hline MP-5940* & 7.603. & 34.72 & 0.133 & $0.511990(05)$ & -12.6 & 1.97 \\
\hline MP-596C* & 9.211 & 38.31 & 0.145 & $0.511882(05)$ & -14.7 & - \\
\hline \multicolumn{7}{|l|}{ Metassedimentos } \\
\hline PALM-2B (1) & 6.903 & 47.32 & 0.088 & $0.512010(04)$ & -12.2 & 1.25 \\
\hline ALO-1 (1) & 5.891 & 27.70 & 0.128 & $0.512219(08)$ & -8.2 & 1.45 \\
\hline ALO-2 (1) & 3.771 & 18.68 & 0.122 & $0.512365(10)$ & -5.3 & 1.12 \\
\hline MORRI-1 (1) & 6.501 & 31.25 & 0.126 & $0.512320(05)$ & -6.2 & 1.25 \\
\hline MAR-1 (1) & 5.540 & 25.71 & 0.130 & $0.512337(05)$ & -5.9 & 1.26 \\
\hline PIRE-1 (2) & 5.435 & 23.52 & 0.139 & $0.511945(05)$ & -13.5 & 2.15 \\
\hline CORU-1 (1) & 5.159 & 23.77 & 0.131 & $0.512371(06)$ & -5.2 & 1.21 \\
\hline ITAPA-1 (1) & 5.530 & 25.55 & 0.130 & $0.512365(06)$ & -5.3 & 1.23 \\
\hline ANA-2 (3) & 4.654 & 25.40 & 0.111 & $0.511535(05)$ & -21.5 & 2.22 \\
\hline $94-1-134 \mathrm{~B}(2)$ & 10.79 & 57.39 & 0.114 & $0.511770(10)$ & -16.9 & 1.93 \\
\hline $94-1-145(1)$ & 6.713 & 31.42 & 0.129 & $0.512320(08)$ & -6.2 & 1.29 \\
\hline $94-2-79(1)$ & 5.940 & 30.42 & 0.118 & $0.511771(05)$ & -16.9 & 2.01 \\
\hline LE-2-137 (1) & 7.669 & 36.88 & 0.126 & $0.511819(12)$ & -16.0 & 2.10 \\
\hline
\end{tabular}

Dados de Pimentel et al. (1992)

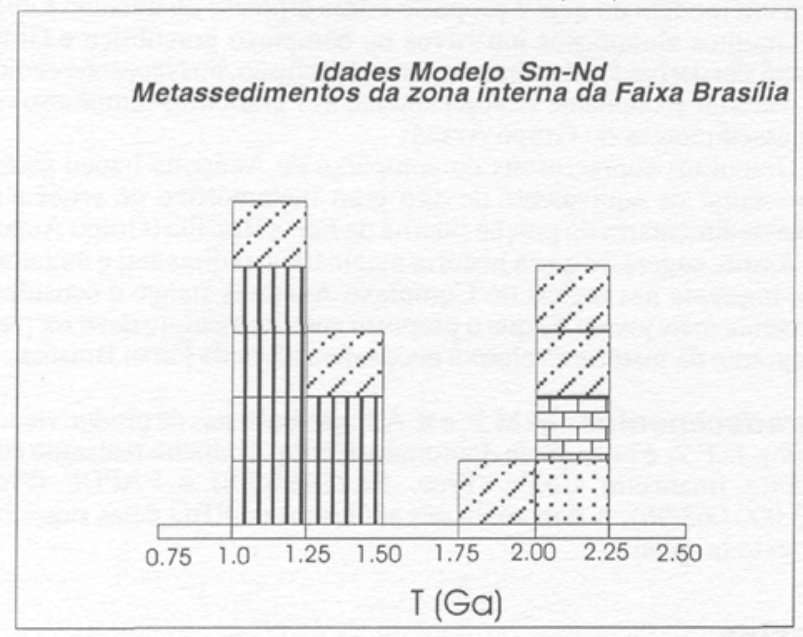

$\because: 2$

quartzito

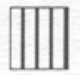

- (granada) micaxisto feldspático

calcixisto

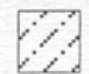

- micaxisto

Figura 4 - Histogramapara os valores de idade modelo dos metassedimentos dos grupos Araxá e Serra da Mesa.

superior para a formação de seus protólitos, sejam eles rochas graníticas ou sedimentares, o que revela que pelo menos algumas das rochas de alto grau do Complexo Anápolis-Itauçu são mais jovens do que o sugerido anteriormente.

As análises isotópicas efetuadas em diversos corpos graníticos expostos regionalmente (Figura 6), intrusivos no Grupo Araxá ou em rochas do complexo granulítico, revelaram razões ${ }^{147} \mathrm{Sm} /{ }^{144} \mathrm{Nd}$ variando no intervalo entre 0,09 e 0,15 . Idades modelo calculadas para rochas com razões $\mathrm{Sm} / \mathrm{Nd}$ menores que 0,13 variam no intervalo entre 1,37 e 1,85, não muito diferente, portanto, do padrão de idades modelo apresentado pelas rochas de alto grau do complexo granulítico (Figura 6). Idades modelo arqueanas não foram encontradas, indicando para a inexistência de crosta continental dessa idadenaregião.Os dados isotópicos para as rochas graníticas são comparáveis com aqueles já obtidos anteriormente por Pimentel et al. (1992) para as

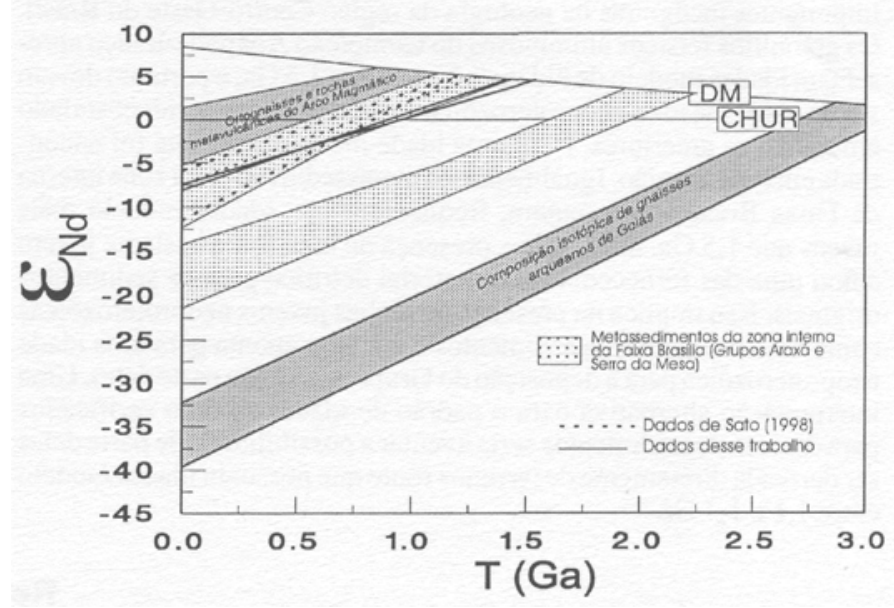

Figura 5 - Características isotópicas de $N$ d de granulitos félsicos aluminosos do Complexo Anápolis-Itauçu. Para comparação estão mostrados também os campos composicionais definidos pelas rochas juvenis neoproterozóicas do Arco Magmático de Goiás, por rochas gnáissicas arqueanas de outras áreas do embasamento da Faixa Brasília e pelos metassedimentos da Faixa Brasília

rochas da Seqüência Maratá, as quais são consideradas por Lacerda Filho e Oliveira (1994) como parte desse grupo de granitos (Fig. 6). Granitos sub-vulcânicos dessa seqüência cristalizaram há ca. de 790 Mae apresentam idades modelo $\mathrm{T}_{\mathrm{DM}}$ de 1,73 e 1,97 . Na mesma região, o granito Sesmaria exposto em meio às rochas do Grupo Araxá, apresenta idade isocrônica $\mathrm{Rb}-\mathrm{Sr}$ de ca. $720 \mathrm{Ma}$ e idades modelo de ca. 1, 1-1,2 Ga (Ribeiro \& Pimentel 1998). Essas constituem as únicas informações geocronológicas disponíveis para esse grupo de granitos da Faixa Brasília e são indicativas, portanto, que esse evento magmático é de idade neoproterozóica. As características químicas das rochas graníticas da região de Ipameri demonstram claramente que se trata de magmatismo de caráter peraluminoso e os magmas originais são, pelo menos em parte, derivados da refusão de metassedimentos do Grupo Araxá (Ribeiro \& Pimentel 1998). 


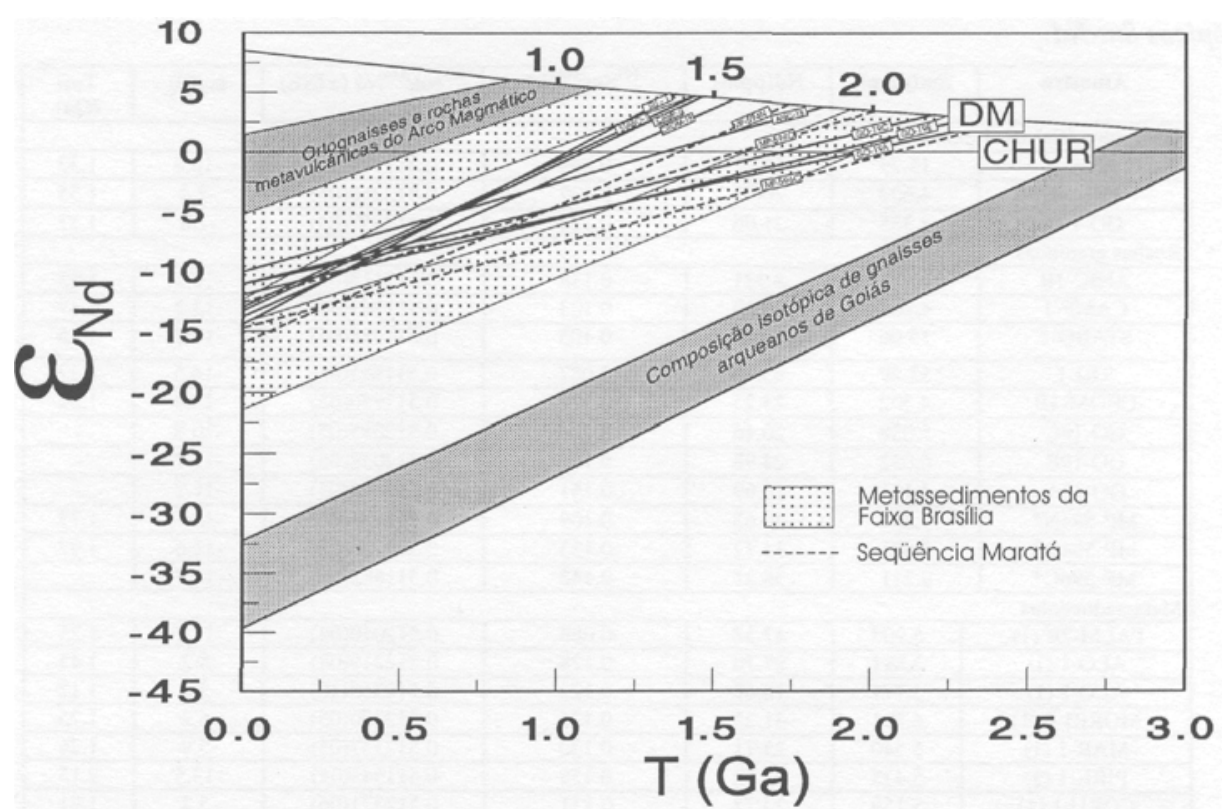

Figura 6 - Características isotópicas de Nd de granitos intrusivos na porção central da Faixa Brasília. Para comparação estão mostrados também os campos composicionais definidos pelas rochas juvenis Neoproterozóicas do Arco Magmático de Goiás, por rochas gnáissicas arqueanas de outras áreas do embasamento da Faixa Brasília e pelos metas sedimento s da Faixa Brasília

CONCLUSÕES Diversas conclusões imediatas são resultantes deste estudo. Elas referem-se especialmente ao estabelecimento de idades máximas para algumas das unidades investigadas, cujas idades precisas de deposição/cristalização original ainda permanecem como importantes incógnitas na geologia da região Centro-Oeste do Brasil. Os granulitos félsicos aluminosos do Complexo Anápolis-Itauçu apresentam idades modelo de $\mathrm{Nd}$ mais jovens que $1,5 \mathrm{Ga}$, e portanto devem ser de idade meso- a neoproterozóica e não arqueanas como postulado em trabalhos anteriores. Nenhuma idade modelo arqueana foi encontrada em toda a região. Igualmente, os metassedimentos da zona interna da Faixa Brasília apresentam, freqüentemente, idades modelo mais jovens que 1,5 Ga, indicando a presença de uma fonte bastante jovem como uma das fornecedoras de material detrítico para os sedimentos originais. Isso implica na presença de rochas juvenis neoproterozóicas como uma das fontes de sedimentos e também aponta para uma idade neoproterozóica para a deposição do Grupo Araxá (ou parte dele). Uma interpretação alternativa para o padrão de idades modelo verificados para esses metassedimentos seria aventar a possibilidade de parte deles ser derivada diretamente de terrenos fonte que possuam idades modelo entre 1,1 e $1,4 \mathrm{Ga}$.
As composições isotópicas de $\mathrm{Nd}$ e os padrões de idade modelo obtidos para os três grupos de rocha investigados são semelhantes entre si (Figuras 5 e 6). Esses dados isotópicos preliminares são consistentes com um modelo no qual é proposto como hipótese de trabalho futuro:

Granitos aluminosos intrusivos no complexo granulítico e Grupo Araxá são derivados dominantemente da refusão, no Neoproterozóico, de material semelhante isotopicamente aos granulitos aluminosos ou metassedimentos do Grupo Araxá;

Granulitos supracrustais do complexo de Anápolis-Itauçu podem representar os equivalente de alto grau metamórfico de seqüências metassedirnentares da porção interna da Faixa Brasília (Grupo Araxá).

Assim, sugere-se que a história magmática, sedimentar e metamórfica impressa nas rochas do Complexo Anápolis-Itauçu é consideravelmente mais jovem do que o proposto anteriormente, e deve ser parte integrante da história evolutiva neoproterozóica da Faixa Brasília.

Agradecimentos M.M.P. e R. A.F. são bolsistas de produtividade, CNPq; D.P.Z. é bolsista de doutorado, CNPq. Trabalho realizado com suporte financeiro $\mathrm{CNPq}$ (Proc. 52.2264/95-8) e FAPDF (Proc. 193.000.068/96). A dois revisores anônimos da RBG pelas sugestões ao texto original.

\section{Referências}

Araújo, V.A. 1994. Programa de levantamentos geológicos básicos do Brasil. Ncrópolis - Folha SE.22-X-B-I. Estado de Goiás. Escala 1: 100.000. Goiânia, DNPM/CPRM, 120p.

Correia, C.T.; Girardi, V.A.V.; Tassinari, C.C.G.; Jost, H. 1997. Rb-Sr and Sm-Nd gcochronology of the Cana Brava layered mafic-ultramafic intrusion, Brazil, and considerations regarding its tectonic.evolution. Rev. Bras. Gcoc., 27:163-168.

Correia, C.T.; Tassinari, C.C.G.; Lambert, D.D.; Kinny, P.; Girardi, V.A.V. 1997. U-Pb (SHRIMP), Sm-Nd and Rc-Os systcmatics of lhe Cana Brava, Niquclândia and Barro Alto layered intrusions in central Bra/.il, and constraints on the tectonic evolution. In: South-American Symposium on Isotope Geology - SSAGI. 1., Extended Abstracts.. IG-USP, Campos do Jordão, pp.88-89.

Danni, J.C.M.; Fuck, R.A.; Leonardos, O.H. 1982. Archaean and lower Protcrozoic units in central Brazil. Geol. Rundschau, 71:291-317.

DcPaolo, D.J. 1981. A ncodymium and strontium isotopic study of the Mcso/.oic calc-alkalinc granitic batholiths of the Sierra Nevada and Peninsular Ranges, California. Jour. Geophys. Rex., 86:10470-10488.

Ferreira Filho, C.F.; Kamo, S.; Fuck, R.A.; Krogh, T.E.; Naldrett, A.J. 1994. Zircon and rutilc $\mathrm{U}-\mathrm{Pb}$ gcochronology of the Niquclândia layered mafic and ultramafic intrusion, Brazil: constraints for the timing of magmatism and high grade mctamorphism. Precamb. Res. 68:241-255.

Lacerda Filho, J.V. \& Oliveira, C.C. 1994. Geologia da região sudeste de Goiás. In: SBG, Simpósio de Geologia do Centro-Ocstc, 4, Anais..., Brasília, p.157-160.

Marini, O.J.; Fuck, R.A.; Danni, J.C.M.; Dardenne, M.A.; Loguércio, S.O.C.; Ramalho, R. 1984. As faixas de dobramentos Brasília, Uruaçu c Paraguai-Araguaia c o Maciço Mediano de Goiás. In: Schobbenhaus, C.; Campos, D.A.; Derzc, G.R.; Asmus, H.E. (coords.) Geologia do Brasil. Brasília, MME/DNPM, 501p.

Pimenicl, M.M. \& Fuck, R.A. 1992. Ncoproterozoic crustal accretion in central Bra/.il. Geology, 20:375-379.
Pimentcl, M.M.; Hcaman, L.; Fuck, R.A. 1991. U-Pb /.ircon and sphene gcochronology of late Protcrozoic volcanic arc rock units from southwestern Goiás, central Bra/.il. Jour. South American Earth Sci., 4:329-339.

Pimcntcl, M.M.; Hcaman, L.; Fuck, R.A. 1992. Idade do mcta-riolito da seqüência Maratá, Grupo Araxá, Goiás: estudo gcocronológico pelos métodos U-Pb cm zircão, $\mathrm{Sm}-\mathrm{Nd}$ c $\mathrm{Rb}-\mathrm{Sr}$. An. Acad. Brás. Ciências, 64:19-28

Pimentcl, M.M.; Whitchousc, M.J.; Viana, M.G.; Fuck, R.A.; Machado, N. 1997. The Mara Rosa arc in the Tocantins Province: further evidence for Ncoprotcrozoic crustal accretion in central Bra/il. Free. Research, 81:299-310.

Ribeiro, R.J.C \& Pimentel, M.M. 1998. Origem dos granitos ncoprotero/.óicos associados ao Grupo Araxá na região de Ipamcri, Goiás: evidências isotópicas pelo método Sm-Nd. In: SBG, Congresso Brasileiro de Geologia, 40., Anais..., Belo Horizonte, p.42.

Stricdcr, A. J. \& Nilson, A.A. 1992. Estudo pctrológico de alguns fragmentos tcctônicos da melange ofiolítica cm Abadiânia (GO). I-O protólito dos corpos de scrpentinito. Rev. Bras. Geoc., 22:338-352.

Suita, M.T.F.; Kamo, S.L.; Krogh, T.E.; Fyfc, W.S.; Hartmann, L.A. 1994. U-Pb ages from the high-grade Barro Alto mafic-ultramafic complex (Goiás, Central Bra/.il): middle Protcrozoic continental mafic magmatism and upper Protcrozoic continental collision. In: InterConfer, on Gcochr. Cosmochr. and Isot. Gcol., 8., Abstracts... Berkeley, USGS, p.309.

Wingc, M. 1995. Evolução dos terrenos granuliticos da Provincia Tocantins, Brasil Central. Tese de Doutoramento. Universidade de Brasília, Brasília, 550 pp (inédito).

Wolff, F 1991 Caracterização petrográfica, litogeoquímica, química mineral e geotermometria de rochas de alto grau metamórfico do Complexo Anápolis-Itauçu, Goiás. Dissertação de Mestrado, Univ. Fed. do Rio de Janeiro, Rio de Janeiro, 148 pp (inédito).

Manuscrito A-1042

Recebido em 6 de novembro de 1998 Revisão dos autores em 15 de fevereiro de 1999 Revisão aceita em 22 de fevereiro de 1999 